\title{
Outcome of patients with pulmonary arterial hypertension referred for lung transplantation: A 14-year single-center experience
}

\author{
Marc de Perrot, MD, John T. Granton, MD, Karen McRae, MD, Andrew F. Pierre, MD, \\ Lianne G. Singer, MD, Thomas K. Waddell, MD, and Shaf Keshavjee, MD
}

Objective: To analyze the outcomes of patients with pulmonary arterial hypertension referred for lung transplantation and determine the changes over time.

\begin{abstract}
Methods: All patients with pulmonary arterial hypertension referred for lung transplantation in our program from January 1997 to September 2010 were reviewed. Pulmonary arterial hypertension was classified as idiopathic $(\mathrm{n}=123)$ or associated with congenital heart disease $(\mathrm{n}=77)$, connective tissue disease $(\mathrm{n}=102)$, or chronic thromboembolic disease $(\mathrm{n}=14)$.
\end{abstract}

\begin{abstract}
Results: After completing their assessment, 61 patients (19\%) were found to be unsuitable for lung transplantation, $38(12 \%)$ refused lung transplantation, $65(21 \%)$ were too early to be listed, and $48(15 \%)$ died before their assessment $(\mathrm{n}=34)$ or being listed $(\mathrm{n}=14)$. Of the 100 patients listed for lung transplantation, 57 underwent bilateral lung transplantation, 22 underwent heart-lung transplantation, 18 died while waiting, and 3 were still waiting. The waiting list mortality was the greatest for patients with connective tissue disease-pulmonary arterial hypertension ( $34 \%$ vs $11 \%$ in the remaining patients, $P=.005)$. The number of patients admitted to the hospital to be bridged to lung transplantation increased from 7\% in the $1997-2004$ cohort to $25 \%$ in the 2005-2010 cohort $(P=.02)$. After lung transplantation, the 30 -day mortality decreased from $24 \%$ in the 1997-2004 group to 6\% in the 2005-2010 group $(P=.007)$. The 10-year survival was worse for those with idiopathic pulmonary arterial hypertension $(42 \%$ vs $70 \%$ for the remaining patients, $P=.01)$. The long-term survival reached $69 \%$ at 10 years in the patients with connective tissue disease pulmonary arterial hypertension.
\end{abstract}

Conclusions: Lung transplantation is an option for about one third of the patients with pulmonary arterial hypertension referred for lung transplantation. The 30-day mortality after lung transplantation improved significantly over time, but the long-term survival remained similar between the two cohorts. Patients with connective tissue disease-pulmonary arterial hypertension have a high mortality on the waiting list but excellent long-term survival. (J Thorac Cardiovasc Surg 2012;143:910-8)

Lung transplantation is the only therapeutic option for patients with pulmonary arterial hypertension (PAH) when medical therapy fails. However, lung transplantation for patients with PAH has generally been hindered by high mortality on the waiting list and in the early posttransplant period. A recent analysis of the United Network for Organ Sharing data demonstrated that the waiting list mortality for patients with idiopathic PAH (iPAH) was $20 \%$ at 1 year after listing, and the mortality after transplantation was $18 \%$ at 1 year after surgery. ${ }^{1}$ The analysis also

From the Toronto Lung Transplant Program and Pulmonary Hypertension Program, Toronto General Hospital, University of Toronto, Toronto, Ontario, Canada. Disclosures: Authors have nothing to disclose with regard to commercial support. Read at the 91st Annual Meeting of the American Association for Thoracic Surgery, Philadelphia, Pennsylvania, May 7-11, 2011.

Received for publication May 7, 2011; revisions received July 21, 2011; accepted for publication Aug 24, 2011; available ahead of print Feb 3, 2012.

Address for reprints: Marc de Perrot, MD, Division of Thoracic Surgery, Toronto General Hospital, 9N-961, 200 Elizabeth Street, Toronto, ON M5G 2C4 Canada (E-mail: marc.deperrot@uhn.on.ca).

0022-5223/\$36.00

Copyright (c) 2012 by The American Association for Thoracic Surgery doi: $10.1016 /$ j.jtcvs.2011.08.055 showed that, in contrast to other indications for lung transplantation, the 1-year mortality for patients with iPAH is predominantly driven by the mortality occurring within the first 30 days after transplantation. ${ }^{1}$ According to the registry from the International Society for Heart and Lung Transplantation, patients with iPAH surviving beyond 30 days after transplantation have long-term outcomes similar to those of patients undergoing lung transplantation for indications other than iPAH. ${ }^{2}$

During the past several years, the perioperative management of patients undergoing lung transplantation has improved substantially, and several experienced centers have reported an overall 30-day mortality of less than 5\% after lung transplantation., ${ }^{3,4}$ The implementation of extracorporeal life support (ECLS) in the pretransplant setting has also helped to successfully bridge an increasing number of patients with respiratory failure to lung transplantation. ${ }^{5}$ The effect of these improvements on the pre- and post-transplant outcome of patients with $\mathrm{PAH}$ is unclear.

The population of patients with PAH undergoing lung transplantation can be divided into three categories 

Abbreviations and Acronyms
$\mathrm{CHD}=$ congenital heart disease
$\mathrm{CT}=$ computed tomography
$\mathrm{CTD}=$ connective tissue disease
$\begin{aligned} \mathrm{CTEPH} & =\text { chronic thromboembolic pulmonary } \\ \text { hypertension } & \end{aligned}$
ECLS = extracorporeal life support
GERD = gastroesophageal reflux disease
iPAH = idiopathic pulmonary arterial hypertension
PAH = pulmonary arterial hypertension
PGD = primary graft dysfunction

according to the most recent pulmonary hypertension classification: iPAH, PAH associated with congenital heart disease (CHD-PAH), and PAH associated with connective tissue disease (CTD-PAH). The number of patients with a diagnosis of iPAH, CHD-PAH, and CTD-PAH represents less than $5 \%$ of all patients undergoing lung transplantation worldwide; therefore, few studies have compared the outcomes of patients with PAH before and after lung transplantation. $^{2}$ In the present study, we reviewed our experience with all patients with PAH referred to the Toronto Lung Transplant Program during the past 14 years and compared the outcomes before and after lung transplantation for iPAH, CHD-PAH, and CTD-PAH. The changes over time were analyzed by comparing two cohorts of patients: 1997 to 2004 and 2005 to 2010.

\section{MATERIALS AND METHODS}

All patients referred for lung or heart-lung transplantation in our program from January 1, 1997 to September 10, 2010 were retrospectively reviewed from a prospectively collected database after the University Health Network Research Ethics Board had approved the study and waived the need for informed consent. The diagnosis was reviewed for all patients with PAH. Patients with PAH were then classified into different categories according to the Dana Point classification. ${ }^{6}$ Heritable and anorexigenmediated PAH were classified with iPAH, because these conditions only involve the pulmonary vasculature. Patients with associated conditions were divided into those with CTD-PAH and CHD-PAH. Patients with $\mathrm{PAH}$ related to portal hypertension, chronic hemolytic anemia, human immunodeficiency virus infection, and schistosomiasis were excluded from the present study, because these patients are rarely or never referred for lung transplantation.

Patients with chronic thromboembolic pulmonary hypertension (CTEPH) who had pulmonary endarterectomy and recurrence of pulmonary hypertension or patients with CTEPH deemed not to be candidates for pulmonary endarterectomy were included in the present study, because these patients can have an underlying PAH component to their disease. ${ }^{6} \mathrm{We}$ were also interested in determining the number of patients with CTEPH referred for lung transplantation since we had started the pulmonary endarterectomy program in our institution in 2005. Ventilation/perfusion scans were used to differentiate PAH from CTEPH. CTEPH was then confirmed by pulmonary angiography and computed tomography (CT) pulmonary angiography. Our indication for pulmonary endarterectomy has evolved over the years, but we currently considered pulmonary endarterectomy for all patients with evidence of chronic thromboembolic disease localized in the segmental arteries or more proximally on the pulmonary angiogram and/or CT pulmonary angiogram, regardless of the degree of right ventricular dysfunction or the severity of the pulmonary vascular resistance.

We recommend that patients with PAH be assessed for transplantation when intravenous epoprostenol is being considered, with a plan to list them when they deteriorate clinically to New York Heart Association class III or IV despite optimal medical therapy, including intravenous epoprostenol. We believe that early assessment is crucial for these patients, even if the time of listing is delayed by several years (through the use of medical treatment) to ensure that patients understand the implication of the transplant option and to be able to provide rapid listing in the event their clinical course is more precarious than expected. The use of intravenous epoprostenol started in 1997 in our institution. In 2006, we implemented the option of ECLS to bridge patients with PAH to lung transplantation. The pumpless Novalung (Novalung GmbH, Hechingen, Germany) connected between the pulmonary artery and the left atrium was used as the preferred option for these patients. $^{7}$

All patients with PAH listed for lung transplantation underwent right heart catheterization before their referral or before being listed. Pulmonary hypertension was defined as a mean pulmonary artery pressure greater than $25 \mathrm{~mm} \mathrm{Hg}$ with a pulmonary capillary wedge pressure of less than $15 \mathrm{~mm}$ $\mathrm{Hg}$. Occasionally, patients with CTD who were deemed too healthy to be listed had their right heart catheterization delayed until the time of listing. In these situations, if right heart catheterization had not been done by September 2010, a calculated pulmonary artery systolic pressure greater than $40 \mathrm{~mm} \mathrm{Hg}$ at rest on the echocardiogram was used to define pulmonary hypertension to ensure that the denominator of patients with CTD-PAH was as complete as possible. Patients with severe interstitial lung disease defined by a total lung capacity less than $60 \%$ were excluded from the present study.

The donor and recipient management has been reviewed in detail elsewhere. ${ }^{8}$ In brief, all donors received intravenous methylprednisolone (15 mg/kg, Solu-Medrol, Upjohn, Don Mills, ON, Canada) after brain death declaration. The donors were maintained euvolemic to avoid excess fluid administration, and vasopressin and/or noradrenaline were often used to maintain adequate blood pressure. Low potassium dextran solution (Perfadex, Vitrolife, Goteborg, Sweden) has been used for all lung preservation since April 1998. A retrograde flush has been added to the anterograde flush since 2001. Severe primary graft dysfunction (PGD) was defined according to the International Society for Heart and Lung Transplantation definition as grade III PGD during the initial 72 hours after transplantation.

Since 1994, the policy in our program has been to offer bilateral lung transplantation to all patients diagnosed with PAH. Heart-lung transplantation was considered only for patients with evidence of severe left ventricular dysfunction (left ventricular ejection fraction $<40 \%$ ) on the echocardiogram and/or the presence of technical limitations to conduct bilateral lung transplantation. Bilateral lung transplantations were performed through a clamshell incision and heart-lung transplantations through a clamshell incision or sternotomy. The approach to bilateral lung transplantation has not changed over time, and all but 1 patient underwent bilateral sequential lung transplantation in the present series. One patient with CHD underwent en bloc double lung transplantation for anatomic reasons.

Organ allocation in Canada has remained the same during the study period. All lung donors located in Ontario were allocated to Toronto. Donors from other provinces were allocated to the local program if there was one. If there was no program, the lungs were sequentially offered to the different lung transplant centers throughout Canada. Transplant physicians from the selected transplant center then chose the recipient on the basis of blood group, size match, patient status, and duration on the waiting list.

To define the changes over time, the patients were divided into 2 cohorts, 1997 to 2004 and 2005 to 2010 . The cutoff between the 2 cohorts was at the time of referral, point of listing, and time of transplantation. Follow-up was complete until September 2010 for all patients. 
TABLE 1. Outcome of patients referred for lung transplantation assessment

\begin{tabular}{|c|c|c|c|c|c|}
\hline Variable & Overall (n) & iPAH (n) & CHD-PAH (n) & CTD-PAH (n) & CTEPH (n) \\
\hline Total patients & 316 & 123 & 77 & 102 & 14 \\
\hline \multicolumn{6}{|l|}{ Period } \\
\hline 1997-2004 & 155 & 64 & 39 & 44 & 8 \\
\hline 2005-2010 & 161 & 59 & 38 & 58 & 6 \\
\hline \multicolumn{6}{|l|}{ Assessment outcome } \\
\hline Unsuitable & $61(19)$ & $20(16)$ & $20(26)$ & $18(18)$ & $3(21)$ \\
\hline Suitable but too early & $69(22)$ & $31(25)$ & $16(21)$ & $19(19)$ & $3(21)$ \\
\hline Death before assessment & $34(11)$ & $13(11)$ & $8(10)$ & $12(12)$ & $1(7)$ \\
\hline Death before listing & $14(4)$ & $5(4)$ & $2(3)$ & $6(6)$ & $1(7)$ \\
\hline Undecided/refused & $38(12)$ & $11(9)$ & $8(10)$ & $18(18)$ & $1(7)$ \\
\hline Listed & $100(32)$ & $43(35)$ & $23(30)$ & $29(28)$ & $5(36)$ \\
\hline
\end{tabular}

Data in parentheses are percentages. $i P A H$, Idiopathic pulmonary arterial hypertension; $C H D$, congenital heart disease; $C T D$, connective tissue disease; $C T E P H$, chronic thromboembolic pulmonary hypertension.

The data are expressed as the mean \pm SD or the median and range. Student $t$ test or 1-way analysis of variance was used to test for differences between the continuous variables, and the chi-square test was used for the categorical variables. Survival was calculated using the Kaplan-Meier method, and survival curves were compared using the log-rank test. GraphPad (GraphPad Software, San Diego, Calif) was used for all analyses.

\section{RESULTS}

Of 2918 patients referred to our program since 1997, 316 $(11 \%)$ presented with PAH (Table 1$)$. PAH was classified as iPAH in 123 , CHD-PAH in 77 , CTD-PAH in 102 , and CTEPH in 14. CTD was related to scleroderma in 83 , lupus erythematosus in 13 , rheumatoid arthritis in 3 , Sjögren syndrome in 2 , and polymyositis in 1 . The number of referrals between the first $(n=155)$ and second $(n=161)$ cohort of patients was similar. The number of referrals for patients with iPAH and CTD-PAH increased over time, and the number of patients with CTEPH referred for lung transplantation decreased after the implementation of our pulmonary endarterectomy program (Figure 1).

After completing their assessment, 100 patients (32\%) were listed for transplantation, $69(22 \%)$ were suitable but too early, $38(12 \%)$ were undecided or refused transplantation, and $48(15 \%)$ died before being assessed $(n=34)$ or listed $(n=14$; Table 1$)$. A total of 61 patients $(19 \%)$ were found to be unsuitable for transplantation. The proportion of unsuitable patients decreased over time (23\% in the first cohort vs $15 \%$ in the second cohort, $P=.07$ ), particularly in patients with CTD-PAH (Table 2). The proportion of patients dying before being assessed or listed did not change over time (Table 2).

A total of 79 patients underwent transplantation, 18 died on the waiting list, and 3 were still alive on the waiting list as of September 2010 (Table 3). The proportion of patients dying on the waiting list was greater for those with CTDPAH than for the other groups of patients with PAH (34\% vs $11 \%$, respectively; $P=.006$ ). In the group of patients diagnosed with $\mathrm{iPAH}$, the mortality on the waiting list decreased significantly between the first and second cohort as a consequence of a greater number of patients admitted to the hospital and started on ECLS to be bridged to transplantation (Table 2). In contrast, the number of patients with CTD-PAH and CHD-PAH admitted to hospital to be bridged to transplantation remained small, and the waiting list mortality did not change over time for these 2 groups of patients.

The vast majority of patients with CHD-PAH underwent heart-lung transplant $(81 \%)$, and the vast majority of patients with $\mathrm{PAAH}$ and CTD-PAH underwent bilateral lung transplantation $(89 \%$ and $94 \%$, respectively). This resulted in a significantly longer time on the waiting list for patients with CHD-PAH than for patients with iPAH and CTD-PAH (Table 3). At transplantation, 2 patients with CHD-PAH required reconstruction of the superior vena cava and inferior vena cava for situs inversus $(\mathrm{n}=1)$ and situs solitus $(\mathrm{n}=1)$, and 1 each underwent replacement of the ascending aorta and aortic arch. In addition, 7 patients underwent repair of the tricuspid valve $(n=3)$, atrial septal defect closure $(n=2)$, patent ductus arteriosus closure $(\mathrm{n}=1)$, and interposition

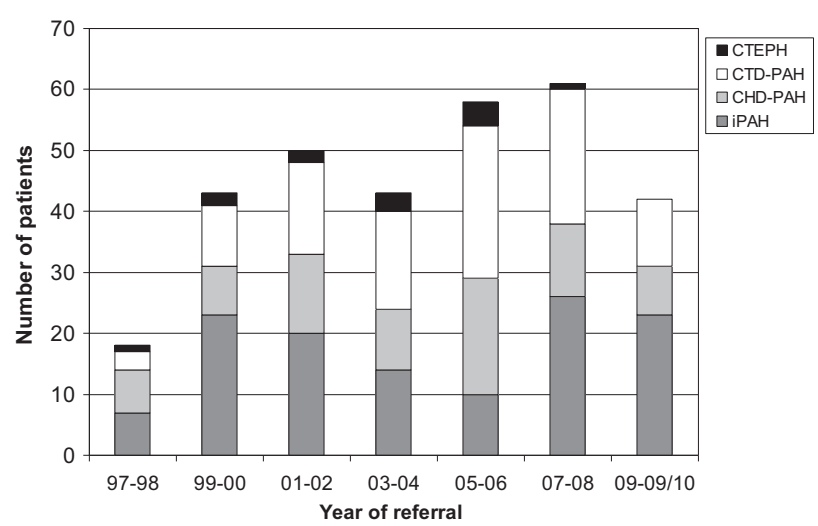

FIGURE 1. Referrals to the Toronto Lung Transplant Program by year according to underlying category of pulmonary arterial hypertension $(P A H)$. $C T E P H$, Chronic thromboembolic pulmonary hypertension; $C T D$, connective tissue disease; $C H D$, congenital heart disease; $i P A H$, idiopathic PAH. 
TABLE 2. Changes over time

\begin{tabular}{|c|c|c|c|}
\hline Variable & 1997-2004 & 2005-2010 & $P$ value \\
\hline \multicolumn{4}{|l|}{ iPAH } \\
\hline Referrals & 64 & 59 & \\
\hline Unsuitable for $\mathrm{Tx}$ & $11(17)$ & $9(15)$ & .8 \\
\hline Died before being assessed or listed & $10(16)$ & $8(14)$ & .7 \\
\hline Undecided/refused & $7(11)$ & $4(7)$ & .4 \\
\hline Patients listed & 20 & 23 & \\
\hline Admitted to hospital to be bridged to $\mathrm{Tx}$ & $1(5)$ & $10(43)$ & .004 \\
\hline ECLS to be bridged to $\mathrm{Tx}$ & 0 & $6(26)$ & .01 \\
\hline Waiting list mortality & $5(25)$ & 0 & .01 \\
\hline Patients transplanted & 13 & 25 & \\
\hline 30-d Mortality after Tx & $3(23)$ & $2(8)$ & .2 \\
\hline Length of ICU stay (d) & $16 \pm 13$ & $32 \pm 29$ & .07 \\
\hline \multicolumn{4}{|l|}{ CTD-PAH } \\
\hline Referrals & 44 & 58 & \\
\hline Unsuitable for $\mathrm{Tx}$ & $12(27)$ & $6(10)$ & .03 \\
\hline Died before being assessed or listed & $12(27)$ & $6(10)$ & .3 \\
\hline Undecided/refused & $8(18)$ & $10(17)$ & .9 \\
\hline Patients listed & 6 & 23 & \\
\hline Admitted to hospital to be bridged to $\mathrm{Tx}$ & 0 & $3(13)$ & .4 \\
\hline ECLS to be bridged to $\mathrm{Tx}$ & 0 & $1(4)$ & .4 \\
\hline Waiting list mortality & $3(50)$ & $7(30)$ & .4 \\
\hline Patients transplanted & 3 & 13 & \\
\hline 30-d Mortality after Tx & $1(33)$ & 0 & .03 \\
\hline Length of ICU stay (d) & $10 \pm 13$ & $15 \pm 10$ & .5 \\
\hline \multicolumn{4}{|l|}{ CHD-PAH } \\
\hline Referrals & 38 & 39 & \\
\hline Unsuitable for $\mathrm{Tx}$ & $11(29)$ & $9(23)$ & 6 \\
\hline Died before being assessed or listed & $6(16)$ & $4(10)$ & .5 \\
\hline Undecided/refused Tx & $4(11)$ & $4(10)$ & .9 \\
\hline Patients listed & 15 & 8 & \\
\hline Admitted to hospital to be bridged to $\mathrm{Tx}$ & $2(13)$ & $1(13)$ & .9 \\
\hline ECLS to be bridged to $\mathrm{Tx}$ & 0 & 0 & NA \\
\hline Waiting list mortality & $1(7)$ & $1(13)$ & .6 \\
\hline Patients transplanted & 12 & 9 & \\
\hline 30-d Mortality after Tx & $3(25)$ & $1(11)$ & 6 \\
\hline Length of ICU stay (d) & $10 \pm 9$ & $9 \pm 7$ & .8 \\
\hline \multicolumn{4}{|l|}{ СТEPH } \\
\hline Referrals & 8 & 6 & \\
\hline Unsuitable for $\mathrm{Tx}$ & $2(8)$ & $1(14)$ & 6 \\
\hline Died before being assessed or listed & $1(13)$ & $1(14)$ & .9 \\
\hline Undecided/refused Tx & 0 & $1(17)$ & NA \\
\hline Patients listed & 3 & 2 & \\
\hline Admitted to hospital to be bridged to $\mathrm{Tx}$ & 0 & 0 & NA \\
\hline ECLS to be bridged to $\mathrm{Tx}$ & 0 & 0 & NA \\
\hline Waiting list mortality & $1(33)$ & 0 & NA \\
\hline Patients transplanted & 1 & 3 & \\
\hline 30-d Mortality after Tx & 0 & 0 & NA \\
\hline Length of ICU stay (d) & 5 & $31 \pm 4$ & NA \\
\hline
\end{tabular}

Data presented as number of patients, with percentages in parentheses or mean \pm standard deviation. $i P A H$, Idiopathic pulmonary arterial hypertension; $T x$, transplantation; $E C L S$, extracorporeal life support; $I C U$, intensive care unit; $C T D$, connective tissue disease; $C H D$, congenital heart disease; $N A$, not applicable; $C T E P H$, chronic thromboembolic pulmonary hypertension.

polytetrafluoroethylene graft to reconstruct an absent right main pulmonary artery $(\mathrm{n}=1)$.

A total of 10 patients died within 30 days of surgery, for an overall 30-day mortality of $13 \%$ (Table 3 ). The 30-day mortality decreased from $24 \%$ in the first cohort to $6 \%$ in the second cohort $(P=.007)$. The 30-day mortality decreased between the first and second cohorts in patients with iPAH, CTD-PAH, and CHD-PAH (Table 2). The 
TABLE 3. Characteristics and outcomes of patients listed for lung transplantation

\begin{tabular}{|c|c|c|c|c|c|c|}
\hline Variable & Overall $(n=100)$ & $\operatorname{iPAH}(n=43)$ & CHD $(n=23)$ & CTD $(n=29)$ & CTEPH $(\mathbf{n}=5)$ & $P$ value \\
\hline Mean PA pressure (mm Hg) & $50 \pm 14$ & $47 \pm 9$ & $67 \pm 14$ & $48 \pm 14$ & $44 \pm 13$ & $<.0001$ \\
\hline Cardiac output (L/min) & $3.5 \pm 0.8$ & $3.7 \pm 0.9$ & $3.3 \pm 0.8$ & $3.5 \pm 0.7$ & $3.1 \pm 1.3$ & .2 \\
\hline NYHA class & $3.3 \pm 0.5$ & $3.2 \pm 0.5$ & $3.3 \pm 0.7$ & $3.3 \pm 0.5$ & $3.3 \pm 0.5$ & .8 \\
\hline 6-min Walk distance (m) & $301 \pm 135$ & $304 \pm 143$ & $289 \pm 175$ & $281 \pm 128$ & $292 \pm 117$ & .9 \\
\hline In hospital to be bridged to $\mathrm{Tx}$ & $17(17)$ & $11(26)$ & $3(13)$ & $3(10)$ & 0 & .5 \\
\hline ECLS to be bridged to $\mathrm{Tx}$ & $7(7)$ & $6(14)$ & 0 & $1(3)$ & 0 & .1 \\
\hline Died on waiting list & $18(18)$ & $5(12)$ & $2(9)$ & $10(34)$ & $1(20)$ & .01 \\
\hline Transplanted & $79(79)$ & $38(88)$ & $21(91)$ & $16(55)$ & $4(80)$ & \\
\hline Alive on waiting list & $3(3)$ & 0 & 0 & $3(11)$ & 0 & \\
\hline Bilateral lung $\mathrm{Tx}$ & $57(72)$ & $34(89)$ & $4(19)$ & $15(94)$ & $4(100)$ & $<.0001$ \\
\hline Heart-lung Tx & $22(28)$ & $4(11)$ & $17(81)$ & $1(6)$ & 0 & \\
\hline Duration on waiting list (d) & $197 \pm 252$ & $81 \pm 71$ & $378 \pm 306$ & $163 \pm 298$ & $263 \pm 152$ & $<.0001$ \\
\hline 30-d Mortality & $10(13)$ & $5(13)$ & $4(19)$ & $1(6)$ & $0(0)$ & .2 \\
\hline Severe primary graft dysfunction* & $18(23)$ & $9(24)$ & $4(19)$ & $4(25)$ & $1(25)$ & .9 \\
\hline Length of ICU stay (d) & $18 \pm 19$ & $26 \pm 25$ & $10 \pm 8$ & $14 \pm 10$ & $25 \pm 13$ & .01 \\
\hline
\end{tabular}

Data presented as mean \pm standard deviation or numbers, with percentages in parentheses. $i P A H$, Idiopathic arterial hypertension; $C H D$, congenital heart disease; $C T D$, connective tissue disease; $C T E P H$, chronic thromboembolic pulmonary hypertension; PA, pulmonary artery; NYHA, New York Heart Association; $E C L S$, extracorporeal life support; $T x$, transplantation; ICU, intensive care unit. *Defined by International Society for Heart and Lung Transplantation grade 3 during initial 72 hours after Tx.

30-day mortality decreased from $30 \%$ to $8 \%$ after heartlung transplantation $(P=.2)$ and from $21 \%$ to $5 \%$ after bilateral lung transplantation $(P=.06)$ between the first and the second cohorts. The rate of severe PGD did not change between the first and second cohorts $(24 \%$ vs $16 \%$, respectively; $P=.4$ ).
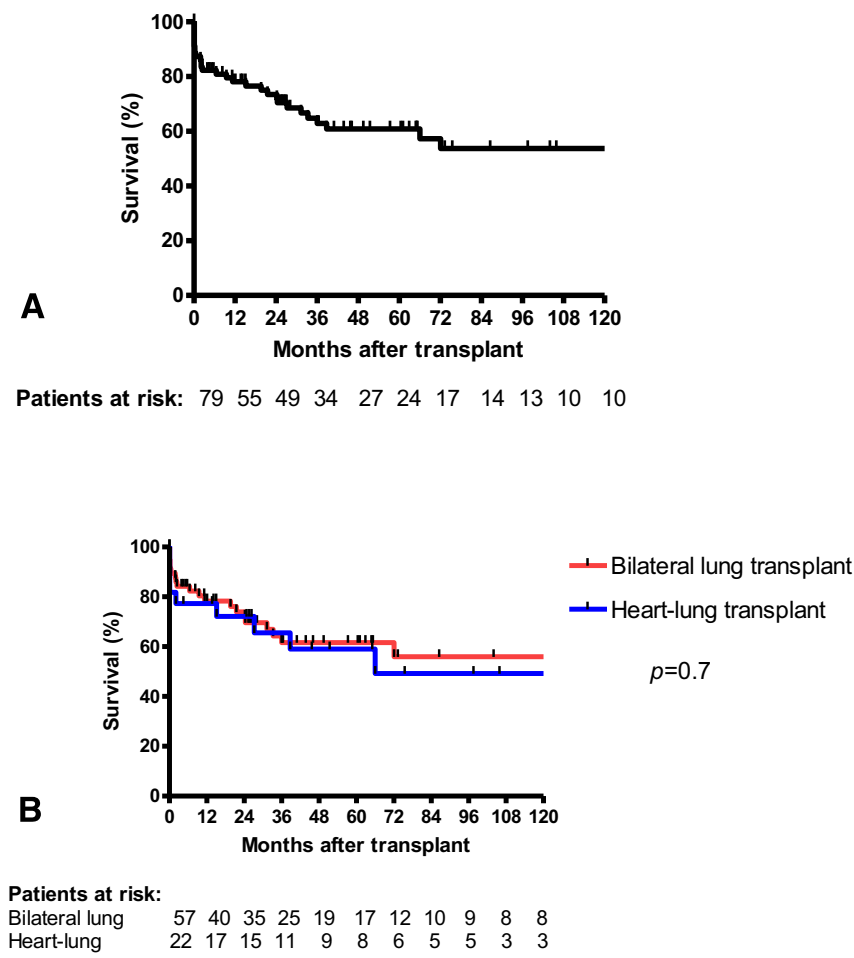

Patients at risk: $\begin{array}{lllllllllll}79 & 59 & 34 & 27 & 24 & 17 & 14 & 13 & 10 & 10\end{array}$

A

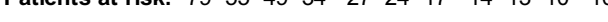

In the long term, the overall 5- and 10-year survival was $61 \%$ and $54 \%$, respectively (Figure 2). The 5- and 10 -year survival was similar after bilateral lung transplantation and heart-lung transplantation (Figure 2). The 10-year survival, however, was worse for patients with iPAH than for the other categories of patients with PAH ( $42 \%$ vs. $70 \%$,
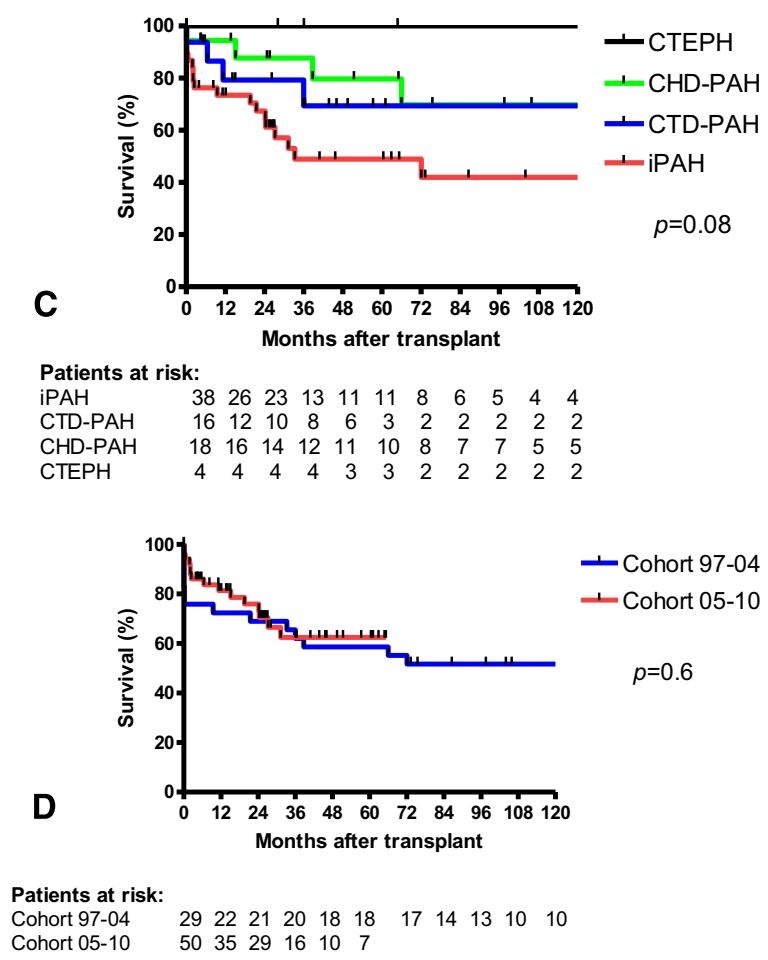

FIGURE 2. Survival after lung transplantation. A, Overall survival; B, survival after bilateral lung and heart-lung transplantation; C, survival according to underlying category of pulmonary arterial hypertension $(P A H)$; and D, survival of patients transplanted in first cohort (cohort 1997-2004) and second cohort (cohort 2005-2010). CTEPH, Chronic thromboembolic pulmonary hypertension; $C T D$, connective tissue disease; $C H D$, congenital heart disease; $i P A H$, idiopathic PAH. 
respectively; $P=.01$ ). Patients with $\mathrm{CHD}-\mathrm{PAH}$ and CTD-PAH achieved excellent long-term outcome with a 10-year survival of $70 \%$ and $69 \%$, respectively (Figure 2). Of the 16 patients with CTD-PAH who underwent transplantation, 13 had scleroderma. Although the 1 -year survival improved from $72 \%$ to $81 \%$ between the first and second cohorts, the long-term outcome was similar between the 2 groups, with 5 -year survival of $59 \%$ in the first cohort and $62 \%$ in the second (Figure 2).

\section{DISCUSSION}

To the best of our knowledge, the present study is the first to analyze the outcomes of all patients with PAH referred for lung transplantation. Our results highlight that, in our experience, $32 \%$ of the patients referred for lung transplantation were listed for transplantation and $25 \%$ eventually underwent transplantation. This reflects that a large number of patients were suitable but too early to be listed because we strongly encourage early referral to be able to rapidly list these patients if their clinical status deteriorates faster than expected. Despite this recommendation, however, we observed that $11 \%$ of the patients still died before being assessed in our program. The proportion of patients dying before being assessed was similar in all PAH categories and did not change over time, suggesting that this was likely related to delayed referrals.

On average, the waiting list mortality was similar between the present study and previous reports at $18 \% .{ }^{1}$ However, the waiting list mortality varied considerably according to the underlying cause of PAH. The waiting list mortality reached $34 \%$ in patients with CTD-PAH and was $9 \%$ in patients with CHD-PAH. In those with $\mathrm{PAH}$, the waiting list mortality decreased from $25 \%$ in the first cohort to $0 \%$ in the second cohort as a consequence of more aggressive management while on the waiting list. Since 2006, we have used the Novalung as a pumpless oxygenator connected between the pulmonary artery and the left atrium to bridge patients with PAH to lung transplantation when medical therapy has failed, including inotropic support. ${ }^{7}$ ECLS was mainly used for patients with iPAH, because these are usually young patients with limited co-morbidities. However, considering the high waiting list mortality for patients with CTD-PAH, this group should potentially also be given the option of ECLS in the future. Although ECLS with either venoarterial extracorporeal membrane oxygenation or pulmonary artery to left atrium Novalung can be associated with major morbidities, an increasing number of centers have been using this option to bridge patients with PAH to lung transplantation with good results. ${ }^{5,9}$

The immediate postoperative recovery and long-term outcomes of patients with CTD-PAH were very good and potentially even better than those for patients transplanted for iPAH. The present series of 19 patients with CTD-PAH undergoing bilateral lung transplantation is one of the largest single-center experience reported. These results support previous reports that have studied the outcomes of patients with CTD undergoing lung transplantation and suggest that the long-term outcomes of patients with CTD is similar to that of other transplanted patients. ${ }^{10,11}$ These results should therefore strongly encourage other programs to consider patients with CTD for lung transplantation.

The degree of gastroesophageal reflux disease (GERD) is always a potential concern in patients with CTD. In our program, all patients undergo esophageal manometry study and 24-hour impedance-pH monitoring of the esophagus at their assessment for lung transplantation. We have observed that the prevalence of GERD is high, regardless of the underlying cause of end-stage lung disease and that the correlation between preoperative GERD and the development of bronchiolitis obliterans syndrome remains unclear. ${ }^{12} \mathrm{We}$ therefore do not disqualify patients from lung transplantation by the severity of GERD alone. Postoperatively, lung transplant recipients are treated according to their clinical symptoms, regardless of the findings on the preoperative workup for GERD. A recent study from Savarino and colleagues ${ }^{13}$ suggested that GERD is more prominent in patients with CTD presenting with severe interstitial lung disease. Hence, considering that we have included only patients with CTD-PAH and excluded those with a total lung capacity of less than $60 \%$ in the present series, the degree of GERD might have been less important than in those with CTD without PAH and the long-term outcomes we observed after lung transplantation in patients with CTD-PAH might not be applicable to CTD patients without PAH.

The 30-day mortality after transplantation improved from $24 \%$ in the first cohort to $6 \%$ in the second cohort. In the second cohort, the 30-day mortality was 5\% after bilateral lung transplantation and $8 \%$ after heart-lung transplantation. This improvement in early mortality after lung transplantation correlates with previous reports showing a significant improvement after lung transplantation in the recent era and likely reflects better management of PGD and right ventricular dysfunction. ${ }^{3}$ This observation also correlates with the recent improvement in operative mortality after pulmonary endarterectomy. The 30-day mortality after elective pulmonary endarterectomy is currently less than $5 \%$ in our institution and other experienced centers. $^{14-16}$

Patients with CHD represent a unique group of patients. Most of these patients require heart-lung transplantation because of their congenital malformation and, thus, the time on the waiting list was longer than for patients with iPAH and CTD-PAH. However, those with CHD-PAH do not decompensate as rapidly as those with CTD-PAH or iPAH, and only 2 of the 23 patients with CHD-PAH who we listed died on the waiting list. This finding correlates with the very good long-term outcomes usually observed for patients with CHD and highlights the difficulty in 
determining the best time to refer these patients for lung or heart-lung transplantation. ${ }^{17}$

The present series included 14 patients with CTEPH. Of these 14 patients, 11 were not candidates for pulmonary endarterectomy because distal disease and 3 had undergone pulmonary endarterectomy at other institutions 6 to 14 years before their referral to our program for lung transplantation. Since the start of our pulmonary endarterectomy program in 2005, the indications for surgery have evolved. We currently considered pulmonary endarterectomy for all patients with evidence of chronic thromboembolic disease localized in the segmental arteries or more proximally on the pulmonary angiogram and/or CT pulmonary angiogram regardless of the degree of right ventricular dysfunction or the severity of the pulmonary vascular resistance. Thus, very few patients with CTEPH have been referred for lung transplantation in our institution since $2008 .{ }^{14}$

The present study had the limitations of a retrospective data collection from a single center, including the analysis of relatively small number of patients, inherent selection bias, and the potential for missing data. We also included all patients with CTD and mean pulmonary artery pressure greater than $25 \mathrm{~mm} \mathrm{Hg}$ associated with a total lung capacity greater than $60 \%$. Although this definition has been used by other groups studying patients with $\mathrm{PAH}$ diagnosed with CTD, we did not re-review the CT scans to document the degree of interstitial lung disease. ${ }^{18,19}$ Considering the good results observed with this group of patients in the present series, future prospective multicenter studies should be performed to confirm our findings and analyze patients with CTD in more detail.

In conclusion, our results have demonstrated that, in our experience, $32 \%$ of patients with PAH referred for lung transplantation are listed for transplantation and $25 \%$ undergo transplantation. The 30-day mortality improved over time for all categories of patients with $\mathrm{PAH}$, although the long-term outcomes remained unchanged. In contrast, the waiting list mortality varied largely with the underlying cause of PAH. The waiting list mortality was $34 \%$ in patients with CTD-PAH but $0 \%$ for patients with iPAH in the most recent cohort of patients. Patients with CTDPAH had excellent early and long-term outcomes after lung transplantation and should potentially be more aggressively treated on the waiting list, using ECLS if necessary.

\section{References}

1. Chen H, Shiboski SC, Golden JA, Gould MK, Hays SR, Hoopes CW, et al. Impact of the lung allocation score on lung transplantation for pulmonary arterial hypertension. Am J Respir Crit Care Med. 2009;180:468-74.

2. Christie JD, Edwards LB, Kucheryavaya AY, Aurora P, Dobbels F, Kirk R, et al. The Registry of the International Society for Heart and Lung Transplantation: twenty-seventh official adult lung and heart-lung transplant report-2010. J Heart Lung Transplant. 2010;29:1104-18.

3. Ailawadi G, Lau CL, Smith PW, Swenson BR, Hennessy SA, Kuhn CJ, et al. Does reperfusion injury still cause significant mortality after lung transplantation? J Thorac Cardiovasc Surg. 2009;137:688-94.
4. Weiss ES, Allen JG, Meguid RA, Patel ND, Merlo CA, Orens JB, et al. The impact of center volume on survival in lung transplantation: an analysis of more than 10,000 cases. Ann Thorac Surg. 2009;88:1062-70.

5. Hämmäinen P, Schersten H, Lemström K, Riise GC, Kukkonen S, Swärd K, et al. Usefulness of extracorporeal membrane oxygenation as a bridge to lung transplantation: a descriptive study. J Heart Lung Transplant. 2011;30:103-7.

6. Simonneau G, Robbins IM, Beghetti M, Channick RN, Delcroix M, Denton CP, et al. Updated clinical classification of pulmonary hypertension. J Am Coll Cardiol. 2009;54(1 Suppl):S43-54.

7. de Perrot M, Granton JT, McRae K, Cypel M, Pierre A, Waddell TK, et al. Impact of extracorporeal life support on outcome in patients with idiopathic pulmonary arterial hypertension awaiting lung transplantation. J Heart Lung Transplant. 2011;30:997-1002.

8. de Perrot M, Waddell TK, Shargall Y, Pierre AF, Fadel E, Uy K, et al. Impact of donors aged 60 years or more on outcome after lung transplantation: results of an 11-year single-center experience. J Thorac Cardiovasc Surg. 2007;133:525-31.

9. Olsson KM, Simon A, Strueber M, Hadem J, Wiesner O, Gottlieb J, et al. Extracorporeal membrane oxygenation in nonintubated patients as bridge to lung transplantation. Am J Transplant. 2010;10:2173-8.

10. Saggar R, Khanna D, Furst DE, Belperio JA, Park GS, Weigt SS, et al. Systemic sclerosis and bilateral lung transplantation: a single centre experience. Eur Respir J. 2010;36:893-900.

11. Shitrit D, Amital A, Peled N, Raviv Y, Medalion B, Saute M, et al. Lung transplantation in patients with scleroderma: case series, review of the literature, and criteria for transplantation. Clin Transplant. 2009;23:178-83.

12. D'Ovidio F, Singer LG, Hadjiliadis D, Pierre A, Waddell TK, de Perrot M, et al. Prevalence of gastroesophageal reflux in end-stage lung disease candidates for lung transplant. Ann Thorac Surg. 2005;80:1254-60.

13. Savarino E, Bazzica M, Zentilin P, Pohl D, Parodi A, Cittadini G, et al. Gastroesophageal reflux and pulmonary fibrosis in scleroderma: a study using pH-impedance monitoring. Am J Respir Crit Care Med. 2009;179:408-13.

14. de Perrot M, McRae K, Shargall Y, Thenganatt J, Moric J, Mak S, et al. Early postoperative pulmonary vascular compliance predicts outcome after pulmonary endarterectomy for chronic thromboembolic pulmonary hypertension. Chest. Epub 2010 Dec 16.

15. Mayer E, Jenkins D, Lindner J, D’Armini A, Kloek J, Meyns B, et al. Surgical management and outcome of patients with chronic thromboembolic pulmonary hypertension: results from an international prospective registry. J Thorac Cardiovasc Surg. 2011;141:702-10.

16. Thistlethwaite PA, Kaneko K, Madani MM, Jamieson SW. Technique and outcomes of pulmonary endarterectomy surgery. Ann Thorac Cardiovasc Surg. 2008; 14:274-82.

17. Gatzoulis MA, Alonso-Gonzalez R, Beghetti M. Pulmonary arterial hypertension in paediatric and adult patients with congenital heart disease. Eur Respir Rev. 2009; 18:154-61.

18. Campo A, Mathai SC, Le Pavec J, Zaiman AL, Hummers LK, Boyce D, et al. Hemodynamic predictors of survival in scleroderma-related pulmonary arterial hypertension. Am J Respir Crit Care Med. 2010;182:252-60.

19. Hachulla E, Launay D, Mouthon L, Sitbon O, Berezne A, Guillevin L, et al. Is pulmonary arterial hypertension really a late complication of systemic sclerosis? Chest. 2009;136:1211-9.

\section{Discussion}

Dr Kenneth R. McCurry (Cleveland, Ohio). Marc, that was a very nice presentation and a very nice paper, and I would like to congratulate you and the rest of your colleagues at the University of Toronto for the very nice manuscript you provided.

This is a rather large series of patients, at least by lung transplant standards, and certainly for the orphan diagnosis of PAH for transplantation from a very experienced center, the University of Toronto. You demonstrate significantly improving 30-day outcomes over a span of 14 years, and I would say excellent longterm outcomes as well, so you are certainly to be congratulated for that. I have 3 questions, Marc, regarding your approach and how you achieved these very good outcomes. First, if I recall correctly, you demonstrated a reduction in 30-day mortality from 
$24 \%$ in your early era to $6 \%$ in the later era, with a fairly low mortality of 5\% in double-lung and $8 \%$ in heart-lung transplantations. I think in your manuscript you attribute this to improved postoperative management. I wonder if you could enlighten us on what your approach is and how you specifically have addressed these patients. As you know, a number of these patients have significant right ventricular dysfunction issues and certainly can experience difficulty perioperatively with primary graft dysfunction.

Dr de Perrot. Thank you, Ken.

Yes, I agree. I think we have improved our perioperative management of RV dysfunction over time, and I think that is certainly what is translating into these results. For all patients with PAH, we use cardiopulmonary bypass. Postoperatively, there are a number of issues, I think, that have progressively changed over time. One is that we don't try to wake up these patients very early. We keep them fully sedated for 2 or even 3 days after the surgery, until the inflammatory condition from the bypass has had time to settle down, the creatinine, if it rises, tends to normalize, and the lactate normalizes. That allows us to keep the right ventricle a little bit more under control. Thus, the lungs usually experience some degree of dysfunction, but by keeping the patient asleep and being able to manage their fluid status more precisely, you avoid that hyperdynamic flow through the lungs, and I think if you wait 2 or 3 days, you allow the lung to recover a little bit. Also, once the inflammatory condition settles down, you can start giving these patients some Lasix and get them drier. They often come to the OR with a large fluid overload and I think it's important to start getting that fluid out as soon as possible once the inflammatory condition settles down. If you don't do that, I think that fluid is progressively being redistributed from the tissue into the vascular compartment and will aggravate the edema otherwise.

Dr McCurry. My second question relates really to the selection of the operation. I think from the data you showed us, the vast majority of congenital heart disease patients received heart-lung transplantations, and most iPAH and CTD patients received double lungs, but there were a few heart-lung transplantations in that patient population, and I think you specifically mentioned a low left ventricular ejection fraction, but do you consider the right ventricle and the degree of RV dysfunction in your decision-making? Obviously you do, so I'm asking you where you draw the line and when do you think you need to go to a heart-lung in iPAH patients or CTD patients.

Dr de Perrot. It's always a very difficult decision and a point of a lot of discussion among our group as well. Clearly, if the left ventricle is dysfunctional, there is no doubt. Most of the patients who had heart-lung transplantation for iPAH or CTD had LV dysfunction. For RV dysfunction, we usually still do a bilateral lung transplant. Even if the RV is significantly dysfunctional, we will still do a bilateral lung transplant. I don't think we have ever done a heart-lung because the RV was too dysfunctional. But it has always led to some discussion in our group. At this point, I don't think we have enough evidence as to when the RV is too far gone and when the RV is fibrotic. The RV has a good capability to recover after the surgery, but it might not fully recover, and certainly it contributes to some difficulty perioperatively. Some of the difficulty is to see how strong the $\mathrm{RV}$ is, and I don't think the cardiac index or other hemodynamic parameters allow you to make a decision as to the strength of the RV. The B-type natriuretic peptide (BNP) or maybe the magnetic resonance imaging in the future will allow us to have a better idea of the myocardium in the RV, but at this point I don't think we have enough data to really tease out the function of the RV. The other parameter is the LV dysfunction. If the LV is dysfunctional on the echocardiographic, then there is no doubt. But what you can see as well is that the LV can be working preoperatively just because there is no flow going to the LV, and once you unload the pulmonary vasculature, the cardiac output to the LV increases and the LV becomes dysfunctional postoperatively. That has been well described. Particularly in Vienna, Walter Klepetko described that a few years ago. So the LV gets some degree of atrophy because of the pulmonary hypertension, and it's also something that's difficult to tease out preoperatively because it's part of the same problem, I think.

Dr McCurry. You have a difficult dilemma sometimes and no clear answer.

I have one final question about your bridging strategies. The data you demonstrated, Marc, showed us an increasing willingness to bridge patients with PAH to lung transplantation. I think 7\% of your population was bridged, and all in the past 5 years. Obviously, you and other groups in Europe have led with the use of the Novalung, and there are a lot of strategies to try to bridge these patients-VV-ECMO, VA-ECMO, balloon septostomy with VV-ECMO, Novalung. Can you give us a bit of insight into what your program thoughts are right now?

Dr de Perrot. Yes. What we mostly use in these patients, or what we use when we can, is the Novalung connected between the pulmonary artery and the left atrium. We use the oxygenator, the Novalung, the membrane without any pump. The RV creates the pump to generate the flow through the Novalung, and that allows unloading of the RV and creates a right-to-left shunt with oxygenation of the blood, which really allows the patient to stabilize immediately once it's connected. Also, because of the central cannulation, it allows the patients to be mobilized.

Once they are extubated and have awakened from the surgery, they can be mobilized until their transplant. We even currently have 1 patient who has been on the PA-LA Novalung for 3 months and is still waiting. So you can really bridge these patients for a number of weeks at least, if not months, by that mechanism. It requires a sternotomy and you can have some difficulty with bleeding, which eventually needs to be controlled, but once things settle down, it's a very nice way to bridge them. The alternative is the VA-ECMO, or the group at the University of Maryland has described the VV-ECMO with an interatrial shunt to generate the flow through the left cavity of the heart. But certainly I would never recommend doing any LVAD for these patients. By putting an LVAD without any oxygenator, you're facing a major problem with potential hypoxemia, as well as bleeding from the cannulas due to the high PA pressure, and you really have to bypass the lungs with whatever technique you use.

Dr McCurry. Thank you, Marc. It was a nice paper and excellent outcomes.

Dr Andrew C. Chang (Ann Arbor, Mich). Dr. de Perrot, I thank you and your colleagues for presenting your experience at Toronto. You had pointed out that about $22 \%$, one fifth of the patients in your cohort, were thought initially to be too well for transplantation. Could you comment on your selection criteria? As you have noted this is a difficult population to decide on listing for transplantation, and I would appreciate your insights in that regard. 
Dr de Perrot. Our recommendation is to really assess these patients early on. At least with the pulmonary hypertension program at Toronto General, when patients go on Flolan, that is typically when we assess these patients, and then we watch them on Flolan, and if they deteriorate on Flolan, and sometimes they can deteriorate relatively quickly, we will be able to list them emergently and have them ready within a few days, and if they do well, then we have the assessment data that we can maintain for several years, and if they come to transplant later, then you repeat a few of the investigations, but at least they know what transplant means, we know they are eligible, and we can list them relatively quickly that way. That's what our recommendation has been. But despite that, what our analysis shows is that you still have $10 \%$ to $15 \%$ of the patients who die even before reaching an assessment. There are fewer patients dying now between the assessment and the listing. That's something that has decreased progressively. But there are still $10 \%, 15 \%$ of the patients who are referred way too late and they don't even make it to an assessment because of the late referral, and that's really something that we try to avoid by having an early referral. But it's always a very difficult decision as to when to list them, when is the right time.
Dr Chang. Do you think there's any utility in using a biochemical marker? Could you elaborate on your use of serum BNP measurement, for example?

Dr de Perrot. Yes. We are using BNP more and more. BNP has been very useful to tease out some of the responses to the PH therapy and to see whether it translates into better outcome if your BNP decreases on any of the $\mathrm{PH}$ medications. So we use it as a marker. We don't really use it once they are on the waiting list. If the BNP is high or the BNP goes up, that certainly can be a sign that suggests that you should potentially list these patients. We should probably use the BNP more often. We have done only a few cases. But one of the difficult decisions is also when you should bridge these patients with the Novalung, extracorporeal life support. Initially, we were really pushing the limit by doing that too late, and 1 patient even arrested on the way to the operating room. I think as we have gotten more confident with ECLS, we have been bridging these patients earlier on, and I think BNP is also one parameter you can follow once you have to put the patients on inotropes. If their BNP doesn't come down or stays very high, this potentially would be an indication to go on ECLS to do it in a better condition than urgently in the middle of the night. 